DOI: $10.2478 / \mathrm{v} .10169-012-0020-1$

\title{
SEISMIC VULNERABILITY FUNCTIONAL METHOD FOR RAPID VISUAL SCREENING OF EXISTING BUILDINGS
}

\author{
MOHAMMADREZA YADOLLAHI ${ }^{1}$, AZLAN ADNAN ${ }^{2}$, \\ ROSLI MOHAMAD ZIN ${ }^{3}$
}

\begin{abstract}
Rapid Visual Screening (RVS) method for buildings was originally developed by the Applied Technology Council (ATC) in the late 1980's for potential seismic hazards. This is a simple and almost a quick way of assessing the building seismic vulnerability score based on visual screening. The logarithmic relationship between final score and the probability of collapse at the maximum considered earthquake (MCE) makes results somewhat difficult to interpret, especially for less technical users. This study is developed to improve the simplicity and usefulness of RVS methodology to determine the numeric scores for seismic vulnerability of buildings using vulnerability functional form. The proposed approach applies the existing method in FEMA 154 (2002) for calculating the building rank based on RVS method. In this study RVS scores are used to evaluate populations of buildings to prioritize detailed evaluations and seismic retrofits. The alternate non-logarithmic format of scoring scheme is much better meeting the needs of the project managers and decision makers, as they require results that are easier to understand. It shows the linear equivalent of RVS final scores which is consistent with the existing ranking systems used in the buildings management program such as budget allocation decision making. The results demonstrate that the weight determined for the factor of "Region Seismicity", which is 0.4033 , has the highest contribution to seismic vulnerability scores of buildings. The applicability of the proposed method is demonstrated through a hypothetical example to rank ten seismically vulnerable buildings.
\end{abstract}

Key words: Risk Reduction, Seismic Vulnerability, Rapid Visual Screening, Buildings.

\section{INTRODUCTION}

Rapid Visual Screening (RVS) is a qualitative seismic vulnerability assessment method. The RVS procedure was developed for a broad audience, including building officials, inspectors, and public and private sector structure owners. The procedure was designed to be the preliminary screening phase of a multi-phase procedure for identifying

\footnotetext{
${ }^{1}$ Department of Structure and Materials, Faculty of Civil Engineering, Universiti Teknologi Malaysia, 81310 Johor, Malaysia, e-mail: ymohammadreza@live.utm.my

2 Department of Structure and Materials, Faculty of Civil Engineering, Universiti Teknologi Malaysia, 81310 Johor, Malaysia.

${ }^{3}$ Construction Technology and Management Center, Universiti Teknologi Malaysia, 81310 Johor, Malaysia.
} 
potentially hazardous structures. Structures identified as potentially hazardous by the RVS procedure should be analyzed in more detail by an experienced seismic design professional. RVS method is developed based on a "sidewalk survey", visual inspection of the structure from the exterior and, if possible, from the interior to identify the primary structural lateral load resisting system(s) and structural materials. The stated purpose of RVS is to classify buildings as either "those acceptable as to risk to life safety or those that may be seismically hazardous" [1]. Because RVS scores show the quantitative measures of the probability of collapse and collapse is the predominant determinant of life safety risk, RVS final scores determine the degrees of life safety risk posed by each building. The intended use of the RVS procedure is to screen a population of buildings on the basis of a cut-off value for the final score, which is used to divide screened buildings into two categories that are expected to: Have acceptable seismic performance, or May be seismically hazardous and should be studied further [1].

This study is developed to improve the simplicity and usefulness of RVS methodology to determine the numeric scores for seismic vulnerability of buildings using linear vulnerability functional form.

A number of guidelines are available from Federal Emergency Management Agency (FEMA) in United States for seismic risk assessment and rehabilitation of buildings. These include FEMA 178 (1992) published in 1989 and revised in 1992, FEMA 310 (1998) developed as revised version of FEMA 178, and FEMA 154 (2002) for rapid visual screening of buildings. Based on the RVS scores, some buildings are selected for preliminary evaluation and further for detailed evaluation. RVS enables users to classify surveyed buildings into two categories: those acceptable as to risk to life safety or those that may be seismically hazardous and should be evaluated in more detail by a design professional, experienced in seismic design. This method has been widely implemented in US and other countries as a practical and simple tool for ranking the buildings regarding seismic vulnerability considerations. For instance, OlshANSKY and Wu [2] evaluated buildings using ATC-21 rapid visual screening and HAZUS99 to estimate earthquake losses for a range of possible earthquake threats in some communities in New Madrid. Accordingly, they took advantage of investments in user-oriented methods that provided for optimal transferability to other communities. In like manner, Wallace and Miller [3] screened 1075 buildings in western Oregon counties in US. They applied RVS to identify potential seismic hazards for Oregon's public facilities, including schools, hospitals, fire stations, police stations, and emergency response centers. Additionally, HoLmes [4] applied the rapid screening method as a tool for mitigate the risk from the expected poor performance of buildings with inadequate seismic design in US. In this regard, a comprehensive study of seismic risk assessment of Gujarat was carried out by SRIKANTH, et al. [5]. Rapid Visual Survey was conducted on 16000 buildings in GandHIDHAm and AdIPUR cities in India. In order to form a strategy of priority based interventions to buildings, Kapetana and Dritsos 
[6] applied RVS to identify, inventory and rank all high-risk buildings in a specified region in Greek.

Considering using RVS method for ranking the buildings, the method itself has been modified by many researchers. For instance, Moseley et al. [7] investigated an alternative screening procedure with significant optimization potential based on fuzzy logic and artificial neural networks; especially when smaller percentages of the buildings with high damage scores are extracted for further investigation. Their results demonstrated that the trained fuzzy logic based rapid visual screening procedure represents a marked improvement when identifying buildings at risk. In particular, when smaller percentages of the buildings with high damage scores are extracted for further investigation, the proposed fuzzy screening procedure becomes more efficient and has significant optimization potential.

WANG and GoETtel [8] reviewed the technical underpinnings of the RVS procedure, with emphasis on the mathematical relationships between RVS scores and the probabilities of building collapse, use of several types of seismic hazard data. The research suggested for using RVS final scores for initial prioritization of seismic retrofits for a large population of public educational buildings in Oregon. The method developed an enhanced RVS methodology called the E-RVS. This approach facilitated the re-evaluation of score modifiers and the improvement of the mathematics for combining score modifiers noted above by making it easier to evaluate the reasonableness of final scoring results.

According to Karbassi and NolLEt [9], a new procedure was proposed based on a set of vulnerability indices for different cities in the province of Quebec in Canada. The structural vulnerability indices were calculated using the improved nonlinear static analysis procedure in FEMA 440. Moreover, based on systematic studies on damage data of the 2001 Bhuj earthquake, SuDHIR et al. [10] proposes a RVS method for RC-frame buildings in India and reviewed some of the available methods for RVS of RC-frame buildings. Sen [11] also proposed a methodology based on the fuzzy logic model and system principles for the classification of buildings into five distinctive but mutually inclusive classes in terms of fuzzy sets. To achieve this, a kind of RVS method was implemented and visually assessable variables were considered as inputs with a single output variable as earthquake hazard category.

Although RVS method was originally developed by the Applied Technology Council [14] in the late 1980's and published in 1988 in the FEMA 154 report, the method has been developed in many different countries. Some of these methods include Turkish-RVS, Greece-RVS, Canada-RVS, Japan-RVS, New Zealand-RVS and Indian-RVS. In this regard, SRIKANTH et al. [5] introduced a brief description of various RVS methodologies.

The logarithmic relationship between final score and the probability of collapse at the MCE in RVS methods makes results somewhat difficult to interpret, especially for less technical users. Because of this limitation, this study presents an alternate non-logarithmic format of scoring scheme to better meet the needs of the project 
managers and decision makers, as they required results that were easier to understand. In this study, based on the most important factors contribute to seismic vulnerability of buildings introduced in FEMA 154 [1], vulnerability functional form is developed to prioritize the building rehabilitation projects. While the proposed method follows the existing RVS scores, the results are presented in non-logarithmic format. Relative weights of vulnerability factors are determined based on Analytical Hierarchy Process (AHP). The scoring method is developed to be compatible with their existing ranking system and provides linear rather than logarithmic scores. Hence, it can be implemented even by non-engineers for data collection and score assignment, because evaluation in the first stage does not require any analysis.

\section{RVS METHOD AND MATERIALS}

As described previously, RVS method is referred to as a "sidewalk survey" in which an experienced screener visually examines a building to identify features that affect the seismic performance of the building; these features may include building type, seismicity, soil conditions and irregularities [1]. RVS is very quick way of assessing the buildings' vulnerability based on visual screening. This method is useful when the number of buildings to be evaluated is large. The visual survey of a building can be completed in less than 30 minutes and can be accomplished from the street without entering into a building [1]. This survey is mainly carried out based on the checklists. A performance score is calculated for each building based on numerical values on the RVS form corresponding to the features of the building. This performance score depends on soil type, building condition, architectural and earthquake resistance features. The performance score is compared to a "cut-off" score to determine whether a building has potential vulnerabilities that should be evaluated further by an experienced engineer. Using these scores, decisions and conclusions on the adequacy of the buildings strengths against earthquake forces likely to occur at the site can be made [5].

\section{RESEARCH METHOD}

Seismic vulnerability factors for any given building can be evaluated independent. It is a rational assumption that each factor has its own functionality and therefore, building vulnerability can be evaluated by a value function. For any given factors $F_{1}, F_{2}, \ldots, F_{p}$, the following value function exists if and only if the criteria are mutually preferentially independent [15]:

$$
G\left(F_{1}, F_{2}, \ldots, F_{p}\right)=\sum_{i=1}^{p} G_{i}\left(F_{i}\right)
$$

where $\mathrm{G}_{i}$ is a single-factor value function over the factor $\mathrm{F}_{i}$. In this study, these factors are compared as to how important they are to the decision makers, with respect to 
the goal. To achieve this, AHP provides a comprehensive and rational framework for structuring a decision problem, for representing and quantifying its factors. AHP was developed by Thomas L. Saaty [12] in the 1970s and has been extensively studied and refined since then. Once the hierarchy is built, the decision makers systematically evaluate its various elements by comparing them to one another two at a time. A numerical weight or priority is derived for each element of the hierarchy, allowing diverse and often incommensurable elements to be compared to one another in a rational and consistent way. In the final step of the process, numerical priority scores are determined for each of the decision alternatives. These numbers represent the alternatives' relative ability to achieve the decision goal, so they allow a straightforward consideration of the various courses of action. Table 1 shows the fundamental relative weights for pair-wise comparisons.

Table 1

The Fundamental Scales for Pair-Wise Comparison.

\begin{tabular}{|c|l|l|}
\hline $\begin{array}{c}\text { Intensity of } \\
\text { Importance }\end{array}$ & Definition & Explanation \\
\hline 1 & Equal importance & Two elements contribute equally to the objective \\
\hline 3 & $\begin{array}{l}\text { Moderate } \\
\text { importance }\end{array}$ & Experience and judgment slightly favour one element over another \\
\hline 5 & Strong importance & Experience and judgment strongly favour one element over another \\
\hline 7 & $\begin{array}{l}\text { Very strong } \\
\text { importance }\end{array}$ & $\begin{array}{l}\text { One element is favoured very strongly over another, its dominance } \\
\text { is demonstrated in practice }\end{array}$ \\
\hline 9 & $\begin{array}{l}\text { Extreme } \\
\text { importance }\end{array}$ & $\begin{array}{l}\text { The evidence favouring one element over another is of the highest } \\
\text { possible orders of affirmation }\end{array}$ \\
\hline Intensities of $2,4,6$ and 8 can be used to express intermediate values. \\
\hline
\end{tabular}

To incorporate the expert judgments regarding the various factors in the hierarchy, decision makers compare the factors in pair. FEMA 154 [1] introduces some important factors which directly contribute to seismic vulnerability score. These factors include region seismicity, structural building type (lateral load resisting system), vertical and plan irregularity, height of buildings, pre-code, post benchmark, soil type and occupancy load. All these factors are grouped into five categories in this study for further hierarchy purpose. If $n$ denoted the number of vulnerability factors, then $\mathrm{N}$, the number of pair-wise comparisons is calculated as follows:

$$
N=\frac{n(n-1)}{2}
$$

According to the above equation, 10 pair-wise comparisons are needed to be done by experts to achieve the reliable results. The five abovementioned groups of factors include seismicity, structural building type, vertical and plan irregularities, pre-code/post 
benchmark and soil type. Therefore, the seismic vulnerability score (SVS) for any given building is introduced as a function of these five factors;

$$
S V S=f\left(V_{b d s}, V_{s b t}, V_{v p i}, V_{p p c}, V_{b s o}\right)
$$

Where, in this equation $\mathrm{V}_{b d s}$ is the vulnerability due to the seismicity region of buildings against earthquake in a specific location; $\mathrm{V}_{s b t}$ is the vulnerability of structural building type; $\mathrm{V}_{v p i}$ is the vulnerability due to vertical and plan irregularities; $\mathrm{V}_{p p c}$ is the vulnerability due to the pre-code/post-benchmark; and $\mathrm{V}_{b s o}$ is the vulnerability of building soil type. It is assumed that all the above values are between zero and ten. Based on vulnerability functional form, Equation 3.3 can be developed into the following form:

$$
S V S=d_{1} \cdot V_{b d s}+d_{2} \cdot V_{s b t}+d_{3} \cdot V_{v p i}+d_{4} \cdot V_{p p c}+d_{5} \cdot V_{b s o}
$$

Where $d_{1}, d_{2} \ldots, d_{5}$ are the weighs of vulnerability factors contribute to building seismic vulnerability. The weights of different vulnerability factors are presented in the following sections based on the judgment of experts and pair comparison analysis.

\section{Vulnerability Score Assignment for Region Seismicity}

The region seismicity for the screening are classified into three main categories, low, moderate and high. The seismicity region $(\mathrm{H}, \mathrm{M}$, or $\mathrm{L})$ is determined by finding the location of the surveyed region on the seismicity map. The relative scores for seismicity of different regions are presented in Table 2 with corresponding spectral acceleration response [13].

Table 2

Vulnerability Score Assignment for Region Seismicity.

\begin{tabular}{|c|c|c|c|}
\hline Region of Seismicity & Low & Moderate & High \\
\hline $\begin{array}{c}\text { Spectral Acceleration } \\
\text { Response, SA (short-period, } \\
\text { or 0.2 sec) }\end{array}$ & $\begin{array}{l}\text { less than 0.167 g (in } \\
\text { horizontal direction) }\end{array}$ & $\begin{array}{c}\text { greater than or } \\
\text { equal to 0.167 g but } \\
\text { less than 0.500 g (in } \\
\text { horizontal direction) }\end{array}$ & $\begin{array}{c}\text { greater than or } \\
\text { equal to 0.500 g (in } \\
\text { horizontal direction) }\end{array}$ \\
\hline $\begin{array}{c}\text { Spectral Acceleration } \\
\text { Response, SA (long-period } \\
\text { or 1.0 sec) }\end{array}$ & $\begin{array}{c}\text { greater than or } \\
\text { less than 0.067 g (in } \\
\text { horizontal direction) } \\
\text { equal to 0.067 g but } \\
\text { less than 0.200 g (in } \\
\text { horizontal direction) }\end{array}$ & $\begin{array}{c}\text { greater than or } \\
\text { equal to 0.200 g (in } \\
\text { horizontal direction) }\end{array}$ \\
\hline $\mathbf{V}_{\text {bds }}$ & $\mathbf{1 - 3}$ & $\mathbf{4 - 7}$ & $\mathbf{8 - 1 0}$ \\
\hline
\end{tabular}

\section{Vulnerability Score Assignment for Structural Building Type}

In the FEMA 154, 15 building types are introduced for RVS procedure with an alpha-numeric reference codes shown in parentheses. These types of buildings are illustrated in Table 3. 
Building Types.

\begin{tabular}{|c|l|c|}
\hline No. & Building Description & Code \\
\hline 1 & $\begin{array}{l}\text { Light wood-frame residential and commercial buildings smaller than or equal } \\
\text { to 5,000 square feet }\end{array}$ & W1 \\
\hline 2 & Light wood-frame buildings larger than 5,000 square fee & W2 \\
\hline 3 & Steel moment-resisting frame buildings & S1 \\
\hline 4 & Braced steel frame buildings & S2 \\
\hline 5 & Light metal buildings & S3 \\
\hline 6 & Steel frame buildings with cast-in-place concrete shear walls & S4 \\
\hline 7 & Steel frame buildings with unreinforced masonry infill walls & S5 \\
\hline 8 & Concrete moment-resisting frame buildings & C1 \\
\hline 9 & Concrete shear-wall buildings & C2 \\
\hline 10 & Concrete frame buildings with unreinforced masonry infill walls & C3 \\
\hline 11 & Tilt-up buildings & PC1 \\
\hline 12 & Precast concrete frame buildings & PC2 \\
\hline 13 & Reinforced masonry buildings with flexible floor and roof diaphragms & RM1 \\
\hline 14 & Reinforced masonry buildings with rigid floor and roof diaphragms & RM2 \\
\hline 15 & Unreinforced masonry bearing-wall buildings & URM \\
\hline
\end{tabular}

For each of these 15 types, a Basic Structural Hazard Score is determined that reflects the estimated likelihood that building collapse will occur if the building is subjected to the MCE ground motions for the region. The Basic Structural Hazard Scores are based on the damage and loss estimation functions provided in the FEMA-funded HAZUS damage and loss estimation methodology [1]. In order to normalize the scores from 1 to 10 , the probability of collapse which presents the complete damage state is selected to assign scores for different building types. Table 4 shows the score assignment for $\mathrm{V}_{s b t}$ in different types of buildings:

The normalized form of $\mathrm{V}_{s b t}$ is determined by the following equation;

$$
\mathrm{V}_{\mathrm{sbt}}=\left|\frac{9(\mathrm{P}-0.03)}{0.12}\right|+1
$$

where $\mathrm{p}$ is the probability of collapse.

\section{Vulnerability Score Assignment for Vertical and Plan Irregularities}

This performance attribute applies to all building types. Examples of vertical irregularity include buildings with setbacks, hillside buildings, and buildings with soft stories. According to score modifiers in three different seismicity regions, score modifiers for "vertical irregularity" range from -1.0 to -4.0 , for various building types and seismicity regions. These score modifiers correspond to increases in the probability of collapse 
Vulnerability Score Assignment for Building Type.

\begin{tabular}{|c|c|c|c|c|c|c|}
\hline \multirow{3}{*}{$\begin{array}{l}\text { Building } \\
\text { Type }\end{array}$} & \multicolumn{6}{|c|}{ Probability of Collapse and Relative Seismic Vulnerability Score } \\
\hline & \multicolumn{2}{|c|}{$\begin{array}{c}\text { Low-Rise } \\
(\leq 3 \text { Stories })\end{array}$} & \multicolumn{2}{|c|}{$\begin{array}{c}\text { Mid-Rise } \\
\text { (4 to } 7 \text { stories) }\end{array}$} & \multicolumn{2}{|c|}{$\begin{array}{c}\text { High-Rise } \\
(\geq 8 \text { Stories })\end{array}$} \\
\hline & $\mathbf{P}$ & SVS & $\mathbf{P}$ & SVS & $\mathbf{P}$ & SVS \\
\hline W1 & 0.03 & 1 & NA & - & NA & - \\
\hline W2 & 0.03 & 1 & NA & - & NA & - \\
\hline S1 & 0.08 & 3.8 & 0.05 & 1.5 & 0.03 & 1 \\
\hline S2 & 0.08 & 3.8 & 0.05 & 1.5 & 0.03 & 1 \\
\hline S3 & 0.03 & 1 & NA & - & NA & - \\
\hline S4 & 0.08 & 3.8 & 0.05 & 1.5 & 0.03 & 1 \\
\hline S5 & 0.08 & 3.8 & 0.05 & 1.5 & 0.03 & 1 \\
\hline $\mathrm{C1}$ & 0.13 & 7.5 & 0.10 & 5.3 & 0.05 & 1.5 \\
\hline $\mathrm{C2}$ & 0.13 & 7.5 & 0.10 & 5.3 & 0.05 & 1.5 \\
\hline $\mathbf{C 3}$ & 0.15 & 10 & 0.13 & 7.5 & 0.10 & 5.3 \\
\hline PC1 & 0.15 & 10 & NA & - & NA & - \\
\hline PC2 & 0.15 & 10 & 0.13 & 7.5 & 0.10 & 5.3 \\
\hline RM1 & 0.13 & 7.5 & 0.10 & 5.3 & NA & - \\
\hline RM2 & 0.13 & 7.5 & 0.10 & 5.3 & 0.05 & 1.5 \\
\hline URM & 0.15 & 10 & 0.15 & 10 & NA & - \\
\hline
\end{tabular}

at the MCE by factors ranging from 10 to 10,000 . Alternatively, score modifiers for "plan irregularity" are -0.8 for the low seismicity region and -0.5 for the moderate and high seismicity regions for all building types. These score modifiers correspond to increases in the probability of collapse at the MCE by factors of 6.31 and 3.16 for the low and moderate-high seismicity regions, respectively. Table 5 shows the relative vulnerability scores for the vertical and plan irregularities $\left(\mathrm{V}_{v p i}\right)$.

The scores in the above table is based on normalized plan and vertical irregularities score derived from FEMA 154. The equations for this normalization are presented below:

$$
\mathrm{V}_{\mathrm{vpi}}=\left\{\begin{array}{c}
0 ; \text { no irregularities exist. } \\
\frac{19.65}{.83-\mathrm{VI}}-3.09 ; \text { no plan irregularity exist. } \\
\frac{19.65}{4.11-\mathrm{PI}}-3.09 ; \text { no vertical irregularity exist. } \\
\frac{-19.65}{\mathrm{PI}+\mathrm{VI}}-3.09 ; \text { PI and VI exist. }
\end{array}\right.
$$


Vulnerability Score Assignment for Vertical and Plan Irregularities.

\begin{tabular}{|c|c|c|c|c|c|c|c|c|c|c|c|c|c|c|c|c|c|}
\hline \multicolumn{18}{|c|}{ Building Type } \\
\hline & & & W1 & W2 & S1 & S2 & S3 & S4 & S5 & C1 & $\mathrm{C2}$ & $\mathrm{C3}$ & PC1 & PC2 & RM1 & RM2 & URM \\
\hline \multirow{9}{*}{ 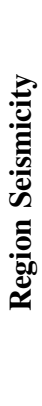 } & \multirow{3}{*}{ 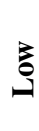 } & V.I & -4 & -3 & -2 & -2 & NA & -2 & -2 & -1.5 & -2 & -2 & NA & -1.5 & -2 & -1.5 & -1.5 \\
\hline & & P.I & -0.8 & -0.8 & -0.8 & -0.8 & NA & -0.8 & -0.8 & -0.8 & -0.8 & -0.8 & NA & -0.8 & -0.8 & -0.8 & -0.8 \\
\hline & & $\mathbf{V}_{\mathrm{vpi}}$ & 1 & 2.1 & 3.9 & 3.9 & NA & 3.9 & 3.9 & 5.5 & 3.9 & 3.9 & NA & 5.5 & 3.9 & 5.5 & 5.5 \\
\hline & \multirow{3}{*}{ 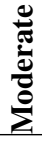 } & V.I & -3.5 & -3 & -2 & -2 & NA & -2 & -2 & -2 & -2 & -2 & NA & -1.5 & -2 & -1.5 & -1.5 \\
\hline & & P.I & -0.5 & -0.5 & -0.5 & -0.5 & NA & -0.5 & -0.5 & -0.5 & -0.5 & -0.5 & NA & -0.5 & -0.5 & -0.5 & -0.5 \\
\hline & & $\mathbf{V}_{\text {vpi }}$ & 1.8 & 2.5 & 4.8 & 4.8 & NA & 4.8 & 4.8 & 4.8 & 4.8 & 4.8 & NA & 6.7 & 4.8 & 6.7 & 6.7 \\
\hline & \multirow{3}{*}{ 을 } & V.I & -2.5 & -2 & -1 & -1.5 & NA & -1 & -1 & -1.5 & -1 & -1 & NA & -1 & -1 & -1 & -1 \\
\hline & & P.I & -0.5 & -0.5 & -0.5 & -0.5 & NA & -0.5 & -0.5 & -0.5 & -0.5 & -0.5 & NA & -0.5 & -0.5 & -0.5 & -0.5 \\
\hline & & $\mathbf{V}_{\text {vpi }}$ & 3.5 & 4.8 & 10 & 6.7 & NA & 10 & 10 & 6.7 & 10 & 10 & NA & 10 & 10 & 10 & 10 \\
\hline
\end{tabular}

\section{Vulnerability Score Assignment for Pre-Code and Post-Benchmark}

Pre-code and post-benchmark are two score modifiers that compare the year which building has been built with the date of initial adoption and enforcement of seismic codes applicable for that building type and the year in which such improvements were adopted is termed the "benchmark" year respectively. According to the benchmark years in RVS procedure, the scores for $\mathrm{V}_{p p c}$ is determined as Equation 7.1; the results are detailed in Table 6 as well.

Table 6

Vulnerability Score Assignment for Pre-Code and Post-Benchmark.

\begin{tabular}{|c|c|c|c|c|c|c|c|c|c|c|c|c|c|c|c|c|c|}
\hline \multicolumn{18}{|c|}{ Building Type } \\
\hline & & & W1 & W2 & S1 & S2 & S3 & S4 & S5 & C1 & C2 & $\mathbf{C 3}$ & PC1 & PC2 & RM1 & RM2 & URM \\
\hline \multirow{12}{*}{ 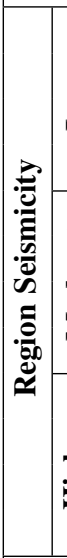 } & \multirow{4}{*}{ 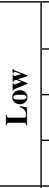 } & P.C & $\mathrm{NA}$ & NA & NA & NA & NA & NA & NA & NA & NA & NA & $\mathrm{NA}$ & NA & NA & NA & NA \\
\hline & & $\mathrm{V}_{p p c}$ & NA & NA & NA & NA & NA & NA & NA & NA & NA & NA & NA & NA & NA & NA & NA \\
\hline & & P.B & 0 & 0.2 & 0.4 & 0.6 & NA & 0.6 & NA & 0.6 & 0.4 & NA & 0.2 & NA & 0.2 & 0.4 & 0.4 \\
\hline & & $\mathrm{V}_{p p c}$ & 7.3 & 6.85 & 6.4 & 5.95 & NA & 5.95 & NA & 5.95 & 6.4 & NA & 6.85 & NA & 6.85 & 6.4 & 6.85 \\
\hline & \multirow[t]{4}{*}{$\cong$} & P.C & 0 & -0.2 & -0.4 & -0.4 & -0.4 & -0.4 & -0.2 & -1 & -0.4 & -1 & -0.2 & -0.4 & -0.4 & -0.4 & -0.4 \\
\hline & & $\mathrm{V}_{p p c}$ & 7.3 & 7.75 & 8.2 & 8.2 & 8.2 & 8.2 & 7.75 & 9.55 & 8.2 & 9.5 & 7.75 & 8.2 & 8.2 & 8.2 & 8.2 \\
\hline & & P.B & 1.6 & 1.6 & 1.4 & 1.4 & $\mathrm{NA}$ & 1.2 & NA & 1.2 & 1.6 & NA & 1.8 & NA & 2 & 1.8 & NA \\
\hline & & $\mathrm{V}_{p p c}$ & 3.7 & 3.7 & 4.15 & 4.15 & NA & 4.6 & NA & 4.6 & 3.7 & NA & 3.25 & NA & 2.8 & 3.25 & NA \\
\hline & \multirow{4}{*}{ 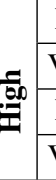 } & P.C & 0 & -1 & $\mid-1$ & $\mid-0.8$ & -0.6 & -0.8 & -0.2 & -1.2 & -1 & -0.2 & -0.8 & -0.8 & -1 & -0.8 & -0.2 \\
\hline & & $\mathrm{V}_{p p c}$ & 7.3 & 9.55 & 9.55 & 9.1 & 8.65 & 9.1 & 7.75 & 10 & 9.55 & 7.75 & 9.1 & 9.1 & 9.55 & 9.1 & 7.75 \\
\hline & & P.B & 2.4 & 2.4 & \begin{tabular}{|l|}
1.4 \\
\end{tabular} & 1.4 & $\mathrm{NA}$ & 1.6 & NA & 1.4 & 2.4 & NA & 2.4 & NA & 2.8 & 2.6 & NA \\
\hline & & $\mathrm{V}_{p p c}$ & 1.9 & 1.9 & 4.15 & 4.15 & NA & 3.7 & NA & 4.15 & 1.9 & NA & 1.9 & NA & 1 & 1.45 & NA \\
\hline & & & & & & & & & & & & & & & & & \\
\hline
\end{tabular}




$$
\mathrm{V}_{\mathrm{ppc}}=\left\{\begin{array}{c}
0 ; \text { no } \mathrm{PC} \text { and } \mathrm{PB} \text { exist. } \\
7.3-2.25 P ; \text { otherwise }
\end{array}\right.
$$

where $\mathrm{P}$ is pre-code or post-benchmark score.

\section{Vulnerability Score Assignment for Building SoIl Type}

Six soil types with measurable parameters are defined in FEMA 154. The normalized scores are presented in Table 7 and can be estimated by Eq. (8.1);

Table 7

Vulnerability Score Assignment due Building Soil Type.

\begin{tabular}{|c|c|c|c|c|c|c|c|c|c|c|c|c|c|c|c|c|c|}
\hline \multicolumn{18}{|c|}{ Building Type } \\
\hline \multicolumn{3}{|c|}{ Soil Type $\downarrow$} & W1 & W2 & S1 & S2 & S3 & S4 & S5 & C1 & C2 & $\mathrm{C3}$ & PC1 & PC2 & RM1 & RM2 & URM \\
\hline \multirow{18}{*}{ 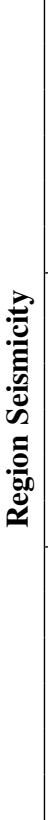 } & \multirow{6}{*}{ נِ } & $\mathrm{C}$ & -0.4 & -0.4 & -0.8 & -0.4 & -0.4 & -0.4 & -0.4 & -0.6 & -0.4 & -0.4 & -0.4 & -0.2 & -0.4 & -0.2 & -0.4 \\
\hline & & $\mathrm{C}$ & 2.64 & 2.64 & 4.27 & 2.64 & 2.64 & 2.64 & 2.64 & 3.45 & 2.64 & 2.64 & 2.64 & 1.82 & 2.64 & .82 & 264 \\
\hline & & $\mathrm{D}$ & -1 & -0.8 & 14 & -1.2 & -1 & -1.4 & -0.8 & 1.4 & -0.8 & -0.8 & & -1 & -08 & 08 & -08 \\
\hline & & $\mathrm{D}$ & 5.09 & 4.27 & 6.73 & 5.91 & 5.09 & 6.73 & 4.27 & 6.73 & 4.27 & 4.27 & 4.27 & 5.09 & 4.27 & 4.27 & 4.27 \\
\hline & & $\mathrm{E}$ & -1.8 & -2 & -2 & -2 & -2 & -2.2 & -2 & -2 & -2 & -2 & -1.8 & -2 & -1.4 & 1.6 & -1.4 \\
\hline & & $\mathrm{E}$ & 8.36 & 9.18 & .18 & 9.18 & 9.18 & 10 & 9.18 & 9.18 & 9.18 & 9.18 & 8.36 & 9.18 & 6.73 & 7.54 & 6.73 \\
\hline & \multirow{6}{*}{ 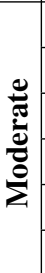 } & $\mathrm{C}$ & -0.2 & -0.8 & -0.6 & -0.8 & -0.6 & -0.8 & -0.8 & -0.6 & -0.8 & -0.6 & -0.6 & -0.6 & -0.8 & -0.6 & -0.4 \\
\hline & & $\mathrm{C}$ & 1.82 & 4.27 & 3.45 & 4.27 & 3.45 & 4.27 & 4.27 & 3.45 & 4.27 & 3.45 & 3.45 & 3.45 & 4.27 & 3.45 & 2.64 \\
\hline & & $\mathrm{D}$ & -0.6 & -1.2 & -1 & -1.2 & -1 & -1.2 & -1.2 & -1 & -1.2 & -1 & -1 & -1.2 & -1.2 & -1.2 & -0.8 \\
\hline & & $\mathrm{D}$ & 45 & 5.91 & .09 & 5.91 & 5.09 & 5.91 & 5.91 & 5.09 & 5.91 & 5.09 & 5.09 & 5.91 & 5.91 & 5.91 & 4.27 \\
\hline & & $\mathrm{E}$ & -1.2 & -1.8 & -1.6 & -1.6 & -1.6 & -1.6 & -1.6 & -1.6 & -1.6 & -1.6 & -1.6 & -1.6 & -1.6 & -1.6 & -1.6 \\
\hline & & $\mathrm{E}$ & & 8.36 & 54 & 7.54 & 7.54 & 7.54 & 7.54 & 7.54 & 7.54 & 7.54 & 7.54 & 7.54 & 7.54 & 7.54 & 7.54 \\
\hline & \multirow{6}{*}{ 㱐 } & $\mathrm{C}$ & 0 & -0.4 & -0.4 & -0.4 & -0.4 & -0.4 & -0.4 & -0.4 & -0.4 & -0.4 & -0.4 & -0.4 & -0.4 & -0.4 & -0.4 \\
\hline & & $\mathrm{C}$ & 1 & 2.64 & 2.64 & 2.64 & 2.64 & 2.64 & 2.64 & 2.64 & 2.64 & 2.64 & 2.64 & 2.64 & 2.64 & 2.64 & 2.64 \\
\hline & & D & 0 & -0.8 & -0.6 & -0.6 & -0.6 & -0.6 & -0.4 & -0.6 & -0.6 & -0.4 & -0.6 & -0.6 & -0.6 & -0.6 & -0.6 \\
\hline & & D & 1 & 4.27 & 3.45 & 3.45 & 3.45 & 3.45 & 2.64 & 3.45 & 3.45 & 2.64 & 3.45 & 3.45 & 3.45 & 3.45 & 3.45 \\
\hline & & E & 0 & -0.8 & -1.2 & -1.2 & -1 & -1.2 & -0.8 & -1.2 & -0.8 & -0.8 & -0.4 & -1.2 & -0.4 & -0.6 & -0.8 \\
\hline & & $\mathrm{E}$ & 1 & 4.27 & 5.91 & 5.91 & 5.09 & 5.91 & 4.27 & 5.91 & 4.27 & 4.27 & 2.64 & 5.91 & 2.64 & 3.45 & 4.27 \\
\hline
\end{tabular}

$$
V_{b s o}=1-4.09 S T
$$

where ST is the score of soil type according to the above table. 


\section{Weight Assignment of Seismic Vulnerability Factors}

As mentioned before, to assign weights of seismic vulnerability factors for buildings, pair-comparison analysis is applied. In order to compare the factors, a team was selected to assign weights. All of the survey participants were experienced building experts. The AHP converts these factors evaluations to numerical values that are processed and compared over the entire range for finding the value SVS. The numerical weights are determined for each factor. These factors are shown in Table 8. The results of pair-wise comparison and the responder's numeric scores are presented and discussed in the following section.

Table 8

Seismic Vulnerability Factors for Buildings.

\begin{tabular}{|c|l|c|c|c|}
\hline $\begin{array}{c}\text { Structure } \\
\text { Category }\end{array}$ & $\begin{array}{c}\text { Seismic Vulnerability Factors } \\
\text { (SVF) }\end{array}$ & Abbreviation & $\begin{array}{c}\text { Number of } \\
\text { Factors }\end{array}$ & $\begin{array}{c}\text { Number of Pair-Wise } \\
\text { Comparison }\end{array}$ \\
\hline \multirow{4}{*}{ Buildings } & Region Seismicity & $\mathrm{V}_{b d s}$ & \multirow{3}{*}{5} & \\
\cline { 2 - 3 } & Structural Building Type & $\mathrm{V}_{s b t}$ & \multirow{2}{*}{5} & \\
\cline { 2 - 3 } & Vertical and Plan Irregularities & $\mathrm{V}_{v p i}$ & & \\
\cline { 2 - 3 } & Pre-Code/Post-Benchmark & $\mathrm{V}_{p p c}$ & & \\
\cline { 2 - 3 } & Building Soil Type & $\mathrm{V}_{b s o}$ & & \\
\hline
\end{tabular}

\section{Results and Discussion}

According to the aforementioned sections and after processing the results from the questionnaires, comparison between the five groups of factors was conducted.

Table 9

Weight Assignment for SVS in Buildings.

\begin{tabular}{|c|c|c|c|c|c|c|c|c|c|c|}
\hline \multicolumn{10}{|c|}{ Weights of Factors based on Pair-Wise Results } \\
\hline Pair-wise Comparison & $\frac{\mathrm{V}_{\mathrm{bds}}}{\mathrm{V}_{\mathrm{sbt}}}$ & $\frac{\mathrm{V}_{\mathrm{bds}}}{\mathrm{V}_{\mathrm{vpi}}}$ & $\frac{\mathrm{V}_{\mathrm{bds}}}{\mathrm{V}_{\mathrm{ppc}}}$ & $\frac{\mathrm{V}_{\mathrm{bds}}}{\mathrm{V}_{\mathrm{bso}}}$ & $\frac{\mathrm{V}_{\mathrm{sbt}}}{\mathrm{V}_{\mathrm{vpi}}}$ & $\frac{\mathrm{V}_{\mathrm{sbt}}}{\mathrm{V}_{\mathrm{ppc}}}$ & $\frac{\mathrm{V}_{\mathrm{sbt}}}{\mathrm{V}_{\mathrm{bso}}}$ & $\frac{\mathrm{V}_{\mathrm{vpi}}}{\mathrm{V}_{\mathrm{ppc}}}$ & $\frac{\mathrm{V}_{\mathrm{vpi}}}{\mathrm{V}_{\mathrm{bso}}}$ & $\frac{\mathrm{V}_{\mathrm{ppc}}}{\mathrm{V}_{\mathrm{bso}}}$ \\
\hline Mean Score & $7 / 2$ & $9 / 2$ & 3 & $3 / 2$ & 2 & $3 / 2$ & 1 & 2 & $1 / 3$ & $1 / 2$ \\
\hline
\end{tabular}

To indicate the importance, factors were evaluated according to their mutual importance in a pair-wise comparison as shown in Table 9. The matrix of findings for the relative weights of pair-wise comparisons is presented below:

$$
D_{\text {Building }}=\left[\begin{array}{ccccc}
1 & 7 / 2 & 9 / 2 & 3 & 3 / 2 \\
2 / 7 & 1 & 2 & 3 / 2 & 1 \\
2 / 9 & 1 / 2 & 1 & 2 & 1 / 3 \\
1 / 3 & 2 / 3 & 1 / 2 & 1 & 1 / 2 \\
2 / 3 & 1 & 3 & 2 & 1
\end{array}\right]
$$


Weights of Seismic Vulnerability Factors in Buildings.

\begin{tabular}{|l|c|c|c|c|c|}
\hline \multicolumn{1}{|c|}{ Factors } & $\begin{array}{c}\text { Region } \\
\text { Seismicity }\end{array}$ & $\begin{array}{c}\text { Structural } \\
\text { Building Type }\end{array}$ & $\begin{array}{c}\text { Vertical and } \\
\text { Plan } \\
\text { Irregularities }\end{array}$ & $\begin{array}{c}\text { Pre-Code/Post- } \\
\text { Benchmark }\end{array}$ & $\begin{array}{c}\text { Building } \\
\text { Soil Type }\end{array}$ \\
\hline Abbreviation & $\mathrm{V}_{b d s}$ & $\mathrm{~V}_{s b t}$ & $\mathrm{~V}_{v p i}$ & $\mathrm{~V}_{p p c}$ & $\mathrm{~V}_{b s o}$ \\
\hline Factors Coefficients & $\mathrm{d}_{1}$ & $\mathrm{~d}_{2}$ & $\mathrm{~d}_{3}$ & $\mathrm{~d}_{4}$ & $\mathrm{~d}_{5}$ \\
\hline Relative Weights & 0.4033 & 0.1667 & 0.1059 & 0.0980 & 0.2261 \\
\hline
\end{tabular}

Non-logarithmic format of scores are very helpful for better understanding the vulnerability scores in buildings. The results show that region seismicity has the highest importance level in buildings, while the factor related to pre-code/post benchmark has the lowest one. This issue indicates that the location of buildings has the highest effect on seismic vulnerability determination. The AHP method for comparison was applied for five factors. 10 pairs of factors were compared by experts to make the AHP matrix. Consistency Ratios (CR) for pair-wise analysis of the responders was 0.0443 . This value is less than 0.1 which indicate acceptable judgments of the responders.

\section{A Hypothetical Example for Seismic Vulnerability Score Assessment}

It is assumed that 10 buildings were composed with different types of structural building as listed in Table 11. The preliminary visual inspections were completed for these buildings and the required data was collected through the field survey.

Table 11

Record of Buildings.

\begin{tabular}{|c|l|c|l|c|c|c|c|c|c|}
\hline $\begin{array}{c}\text { Buil- } \\
\text { ding } \\
\text { Code }\end{array}$ & $\begin{array}{c}\text { Seismicity } \\
\text { Region }\end{array}$ & $\begin{array}{c}\text { Structural } \\
\text { Building } \\
\text { type }\end{array}$ & Height & $\begin{array}{c}\text { Vertical } \\
\text { Irregu- } \\
\text { larity }\end{array}$ & $\begin{array}{c}\text { Plan } \\
\text { Irregu- } \\
\text { larity }\end{array}$ & $\begin{array}{c}\text { Year } \\
\text { seismic } \\
\text { code } \\
\text { initially } \\
\text { adopted }\end{array}$ & $\begin{array}{c}\text { Bench- } \\
\text { mark } \\
\text { year } \\
\text { when } \\
\text { codes } \\
\text { improved }\end{array}$ & $\begin{array}{c}\text { Year } \\
\text { built }\end{array}$ & $\begin{array}{c}\text { Soil } \\
\text { type }\end{array}$ \\
\hline B1 & Moderate & S3 & Low-Rise & - & - & 1941 & None & 1983 & C \\
\hline B2 & Very high & S4 & Mid-Rise & + & + & 1941 & 1976 & 1986 & E \\
\hline B3 & High & C2 & High-Rise & - & + & 1941 & 1976 & 1972 & D \\
\hline B4 & Moderate & C3 & Low-Rise & + & - & 1933 & None & 1979 & D \\
\hline B5 & Moderate & S1 & Mid-Rise & + & - & 1933 & 1994 & 1995 & C \\
\hline B6 & Low & S5 & Low-Rise & - & + & 1933 & None & 1990 & C \\
\hline B7 & Very low & C1 & Mid-Rise & - & - & 1933 & 1976 & 1985 & E \\
\hline B8 & High & S4 & Mid-Rise & - & + & 1941 & 1976 & 1970 & D \\
\hline B9 & High & S3 & Low-Rise & - & - & 1941 & None & 1978 & C \\
\hline B10 & Moderate & S3 & Mid-Rise & - & - & 1941 & None & 1992 & E \\
\hline
\end{tabular}


Five scores which contribute in SVS estimation were calculated and results are shown in Table 12. Because of the normalization in SVS equations, the scores are all range from 0 to 10 . Higher scores indicate higher seismic vulnerability in pertinent building. Higher scores, consequently, lead to higher rank or priority in rehabilitation or retrofit tasks. The results in Table 12 illustrate the first priority among these ten building is building B2.

Table 12

The Results of Seismic Vulnerability Scores for Selected Buildings.

\begin{tabular}{|c|c|c|c|c|c|c|c|}
\hline $\begin{array}{c}\text { Building } \\
\text { Code }\end{array}$ & $\mathbf{V}_{\text {bds }}$ & $\mathbf{V}_{\text {sbt }}$ & $\mathbf{V}_{\text {vpi }}$ & $\mathbf{V}_{\text {ppc }}$ & $\mathbf{V}_{\text {bso }}$ & SVS & $\begin{array}{c}\text { Seismic } \\
\text { Priority }\end{array}$ \\
\cline { 1 - 5 } Weights & 0.4033 & 0.1667 & 0.1059 & 0.0980 & 0.2261 & & \\
\hline B1 & 5 & 1 & 0 & 0 & 3.45 & 2.95 & $\mathbf{9}$ \\
\hline B2 & 10 & 2 & 4.77 & 3.7 & 5.91 & 6.55 & $\mathbf{1}$ \\
\hline B3 & 8 & 2 & 1.17 & 0 & 3.45 & 4.45 & $\mathbf{4}$ \\
\hline B4 & 5 & 10 & 3.85 & 0 & 5.09 & 5.23 & $\mathbf{2}$ \\
\hline B5 & 6 & 2 & 3.85 & 4.15 & 3.45 & 4.34 & $\mathbf{6}$ \\
\hline B6 & 3 & 4 & 0.91 & 0 & 2.64 & 2.56 & $\mathbf{1 0}$ \\
\hline B7 & 1 & 6 & 0 & 5.95 & 9.18 & 4.06 & $\mathbf{8}$ \\
\hline B8 & 9 & 2 & 1.17 & 0 & 3.45 & 4.85 & $\mathbf{3}$ \\
\hline B9 & 9 & 1 & 0 & 0 & 2.64 & 4.38 & $\mathbf{5}$ \\
\hline B10 & 6 & 0 & 0 & 0 & 7.54 & 4.11 & $\mathbf{7}$ \\
\hline
\end{tabular}

\section{Conclusion}

The RVS procedure is a simple method in the preliminary screening phase for identifying potentially hazardous buildings. The primary use of RVS score is to sort a population of buildings into those that require further engineering study and those that probably have acceptable seismic performance. The logarithmic relationship between seismic vulnerability scores and the probability of collapse makes RVS results somewhat difficult to interpret, especially for less technical users. Using AHP, the proposed scoring system for seismic vulnerability assessment of existing buildings based on RVS is made to be compatible with their existing ranking system. The proposed method provides linear rather than logarithmic scores. All factors regarding buildings seismic vulnerability factors are evaluated and relative scores are assigned based on expert judgments. Nevertheless, it is important to remember that RVS is a preliminary screening tool, based on the limited information available from a sidewalk survey (or brief interior inspection). The method was also implemented with a hypothetical example in order to rank 10 buildings with different characteristics. The results were obtained as numeric scores based on linear method. The results demonstrate the feasibility and effectiveness of the proposed vulnerability functional form to prioritize the buildings. 
Furthermore, results revealed that the score determined for the factor of "Region Seismicity", has the highest contribution to seismic vulnerability scores of buildings. In addition, about $40 \%$ of contribution in seismic vulnerability score of buildings belongs to the location of building. The linear scoring system reflects preliminary seismic risk and is easier to integrate into the existing needs than traditional RVS scores. It should be reminded that the numeric weights determined through the questionnaire survey can be scrutinized by local experts for any specific location.

\section{REFERENCES}

1. FEMA 154, Edition 2. (March 2002). Rapid Visual Screening of Buildings for Potential Seismic Hazards, A Handbook, Applied Technology Council, Washington, DC.

2. R.B. Olshansky, Y. Wu, Evaluating Earthquake Safety in Mid-American Communities, Natural Hazards Review, 5(2), 71-81, 2004.

3. N.M. Wallace, T.H. Miller, Seismic Screening of Public Facilities in Oregon's Western Counties, Practice Periodical on Structural Design and Construction, 13(4), 189-197, 2008.

4. W.T. Holmes, Progress of Seismic Rehabilitation of Buildings in the U. S., Conference on Improving the Seismic Performance of Existing Buildings and Other Structures, San Francisco, California, 17-31, 2009.

5. T. Srikanth, R.P. Kumar, A.P. Singh, B.K. Rastogi, S. Kumar, Earthquake Vulnerability Assessment of Existing Buildings in Gandhidham and Adipur Cities Kachchh, Gujarat (India), European Journal of Scientific Research, 41(3), 336-353, 2010.

6. P. Kapetana, S. Dritsos, Seismic assessment of buildings by rapid visual screening procedures, $6^{\text {th }}$ International Conference on Earthquake Resistant Engineering Structures, Bologna, Italy, 2007.

7. http://apps.isiknowledge.com.ezproxy.psz.utm.my/OneClickSearch.do?product=UA\&search_mode=

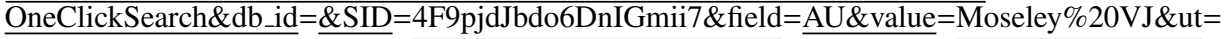
$\overline{000249072500006 \& \text { pos }}=\underline{1}$ V.J. Moseley, S.E. Dritsos, D.L. Kolaksis, Pre-earthquake fuzzy logic and neural network based rapid visual screening of buildings, Structural Engineering and Mechanics, 27(1), 77-97, 2007.

8. Y. Wang, K.A. Goettel, Enhanced Rapid Visual Screening (E-RVS) Method for Prioritization of Seismic Retrofits in Oregon, State Geologist State of Oregon Department of Geology and Mineral Industries, Special Paper 39, Oregon Department of Geology and Mineral Industries, 2007.

9. A. Karbassi, M.J. Nollet, Development of an index assignment procedure compatible with the regional seismicity in the province of Quebec for the rapid visual screening of existing buildings, Canadian Journal of Civil Engineering, 35(9), 925-937, 2008.

10. K.J. Sudhir, M. Keya, M. Kumar, M. Shah, A Proposed Rapid Visual Screening Procedure for Seismic Evaluation of RC-Frame Buildings in India, Earthquake Spectra, 26, 709-729, 2010.

11. Z. SEN, Rapid visual earthquake hazard evaluation of existing buildings by fuzzy logic modelling. Expert Systems with Applications, 37, 5653-5660, 2010.

12. T.L. SaAty, Relative Measurement and its Generalization in Decision Making: Why Pairwise Comparisons are Central in Mathematics for the Measurement of Intangible Factors, The Analytic Hierarchy/Network Process. RACSAM (Review of the Royal Spanish Academy of Sciences, Series A, Mathematics), 102(2), 251-318, 2008-06.

13. FEMA 356 (Prestandard- 2000). Prestandard and Commentary for the Seismic Rehabilitation of Buildings, American Society of Civil Engineers (ACSE), Federal Emergency Management Agency, Washington, D.C., November 2000. 
14. Applied Technology Council (ATC-1988). Rapid visual screening of buildings for potential seismic hazards: A handbook. Prepared for Federal Emergency Management Agency, Washington D.C.

15. NCHRP, Report 590, Multi-Objective Optimization for Bridge Management Systems, Transportation Research Board, National Cooperative Highway Research Program, March 2007.

Remarks on the paper should be sent to the Editorial Office

no later than December 31, 2012
Received January 01, 2012 revised version August 10, 2012 